\title{
Immunocytochemical and Neurochemical Evidence for Age-Related Loss of GABA in the Inferior Colliculus: Implications for Neural Presbycusis
}

\author{
D. M. Caspary, A. Raza, B. A. Lawhorn Armour, J. Pippin, and S. P. Arnerić \\ Southern Illinois University School of Medicine, Springfield, Illinois 62794-9230
}

The present study describes substantial, selective, age-related loss of the putative inhibitory neurotransmitter GABA in the central nucleus of the inferior colliculus $(\mathrm{CIC})$ of rat based on immunocytochemical and neurochemical data. For immunocytochemistry, neurons in the CIC were immunolabeled using an antibody against a GABA conjugate in young adult (2- to 7-month-old) and aged (18- to 29-month-old) Fischer-344 rats. Computer-assisted morphometry was then used to generate maps of GABA-immunoreactive neurons in the CIC. The number of GABA-positive neurons was reduced $36 \%$ in the ventrolateral portion of the CIC of aged animals (93 neurons $/ \mathrm{mm}^{2}$ ) compared to their matched young adult cohorts (145 neurons $/ \mathrm{mm}^{2} ; p<0.01$ ). For neurochemistry, basal and $\mathrm{K}^{+}$-evoked release of the endogenous amino acids GABA, glutamate (Glu), aspartate (Asp), and tyrosine (Tyr) from micropunches of the $\mathrm{ClC}$ were measured in 8 agepaired animals from the 2 age groups using high-performance liquid chromatography. Overflow of radiolabeled acetylcholine ( $\left.{ }^{3} \mathrm{H}-\mathrm{ACh}\right)$ was also determined. In both age groups, $\mathrm{K}^{+}$-evoked release of GABA, Glu, Asp, and ${ }^{3} \mathrm{H}-\mathrm{ACh}$ from CIC punches was significantly enhanced above basal efflux $(+200,+215,+163$, and $+309 \%$, respectively), while Tyr release was unchanged. Evoked release of ${ }^{3} \mathrm{H}-\mathrm{ACh}$ and all amino acids except Tyr showed substantial $\mathrm{Ca}^{2+}$ dependence. A significant $(p<0.05)$ age-related reduction in both basal $(-35 \%)$ and $K^{+}-$stimulated $(-42 \%)$ efflux of GABA from the $\mathrm{CIC}$ was observed. A corresponding decrease in postrelease tissue content of GABA in $\mathrm{ClC}$ of aged rats was observed $(-30 \%, p<0.05)$. In contrast, tissue content as well as basal and evoked release of Glu, Asp, Tyr, and ${ }^{3} \mathrm{H}-\mathrm{ACh}$ was similar between the 2 age groups. Age-related GABA neurochemical changes described in the CIC were not observed in the release of the other amino acids or ${ }^{3} \mathrm{H}-\mathrm{ACh}$

Received Sept. 7, 1989; revised Feb. 6, 1990; accepted Feb. 15, 1990.

We wish to thank Kelly Rourke and Martha Downen for early work on immunocytochemistry, Cynthia R. Kelley for assistance in performing the amino acid determination, and Dawn Melcher for help with the manuscript. The neurochemical data presented were completed by Ahmad Raza in partial fulfillment of dissertation requirements at S.I.U. School of Medicine. We especially thank Christine Jeffrey-Wiseman for her assistance with the imaging and data analysis, and Dr. Steven Verhulst for his expertise with the statistics. Useful criticism was provided by Drs. Gregory Brewer and Wes Ashford. Biomedical Illustration helped with the figures. This work was supported by the Deafness Research Foundation American Federation on Aging Research, and DC00151 to D.M.C.; Central Research Committee of Southern Illinois University School of Medicine and NIA N01-AG-2104 to S.P.A.

Correspondence should be addressed to Donald M. Caspary, Ph.D., Department of Pharmacology, Southern Illinois Iniversity School of Medicine, PO Box 19230, Springfield, IL 62794-9230.

Copyright (c) 1990 Society for Neuroscience $0270-6474 / 90 / 072363-10 \$ 03.00 / 0$ from either the rostral ventrolateral medulla or the somatosensory cortex, 2 brain regions involved in processing nonauditory sensory input. These data support previous findings that GABA, Glu, Asp, and ACh may subserve neurotransmission in the CIC. Additionally, these data provide clear evidence for a pronounced, region- and neurotransmitterselective, age-related reduction of GABA in the CIC. These findings support the hypothesis that impairment of inhibitory GABAergic neurotransmission in the $\mathrm{CIC}$ may contribute to abnormal auditory perception and processing seen in neural presbycusis.

The central nucleus of the inferior colliculus (CIC) is an important auditory processing center receiving ascending inputs from the cochlear nuclei (CN), superior olivary complex (SOC), nuclei of the lateral lemniscus (NLL), and commissural projections from the contralateral IC, as well as indirect descending inputs from the auditory cortex (Morest and Oliver, 1984; FayeLund and Osen, 1985; Coleman and Clerici, 1987; Oliver et al., 1987).

Neurons in the CIC code for the localization of sound in space (see Aitkin, 1986; Carney and Yin, 1989, for review) and are sensitive to differences in interaural time showing both shortand long-duration inhibitory responses (Kuwada et al., 1980; Carney and Yin, 1989). An important role for GABA as a neurotransmitter in the $\mathrm{IC}$ has been suggested by a number of neurochemical, immunocytochemical, and pharmacological studies. The IC has been found to contain high levels of GABA and shows high activity of glutamic acid decarboxylase (GAD) and GABA-transaminase (GABA-T), enzymes responsible for the synthesis and degradation of GABA, respectively (Tachibana and Kuriyama, 1974; Fisher and Davies, 1976; Adams and Wenthold, 1979; Contreras and Bachelard, 1979). These data are further supported by dense levels of immunocytochemical staining for GABA, GAD, and GABA-T in the IC (Ottersen and Storm-Mathisen, 1984; Nagai et al., 1985; Thompson et al., 1985; Moore and Moore, 1987).

Neuropharmacological studies using iontophoretic application of GABA and GABA antagonists specifically implicate GABA as an inhibitory neurotransmitter in the IC (Faingold et al., 1989). Intracellular recordings from IC neurons in vivo and in vitro display IPSPs which can be blocked by picrotoxin, while bicuculline has been shown to block extracellularly recorded binaural inhibition (Kuwada et al., 1980; Moiseff, 1985; Faingold et al., 1986; Smith, 1986). Moreover, the processing of acoustic information in the $\mathrm{IC}$, including binaural processing and intensity coding, is shaped by the inhibitory neurotrans- 
mitter GABA (Faingold et al., 1989). Neural presbycusis, which includes loss of the ability to detect signals in noise and loss of speech understanding in many individuals without substantial losses in pure-tone thresholds in quiet, may be related to selective loss of inhibition in the IC. In addition, functional and behavioral evidence in humans and rats indicates corresponding age-related changes in the auditory brain-stem response (ABR), IC changes in glucose utilization, protein synthesis, GABAligand receptor binding, and the ability to localize sound (Harrison, 1981; London et al., 1981; Kendall et al., 1982; Brown, 1984; Ingvar et al., 1985; Simpson et al., 1985; Smith et al., 1986). In light of these findings and recent preliminary data (Caspary and Lawhorn, 1987), we have begun a series of studies to examine the hypothesis that age-related loss of inhibitory GABAergic neurotransmission in the CIC may contribute to abnormal auditory perception and processing seen with neural presbycusis.

The present study specifically sought to explore the following questions: (1) Is there an age-related, region-selective loss of GABA-containing neurons in the CIC? (2) If so, is the loss correlated with a reduction of GABA release? (3) Do other neurotransmitter systems in IC demonstrate corresponding agerelated impairments? Immunocytochemical and neurochemical evidence is provided that indicates a substantial neurotransmitter- and region-selective loss of GABA in the CIC of aged Fischer-344 rats.

\section{Materials and Methods}

Immunocytochemistry. Eight young adult (2- to 31/2-month-old, 250$300 \mathrm{gm}$ ) and 8 aged (18- to 29-month-old, $350-450 \mathrm{gm}$ ) Fischer-344 rats were paired to process the animals simultaneously. All animals utilized in the present study were otoscopically examined and were determined to have normal external and middle ears. For transcardiac perfusions, animals were deeply anesthetized with $\mathrm{Ketamine}-\mathrm{HCl}$ at a dose of $100-150 \mathrm{mg} / \mathrm{kg}$. A peristaltic pump was used to deliver $50 \mathrm{ml}$ $0.1 \mathrm{M}$ sodium cacodylate, $\mathrm{pH} 7.4$, followed by $4 \%$ formaldehyde and $2 \%$ glutaraldehyde in $0.1 \mathrm{~m}$ sodium cacodylate, $\mathrm{pH} 7.4$. Brains were carefully removed from the calvarium, blocked, and postfixed for $6-8$ $\mathrm{hr}$ in $4 \%$ formaldehyde and $2 \%$ glutaraldehyde in $0.1 \mathrm{M}$ sodium cacodylate, $\mathrm{pH}$ 7.4. Tissue blocks were then infiltrated with a graded series of phosphate-buffered sucrose $(10-30 \%)$ and stored until further processing.

A sliding microtome was used to cut $12 \mu \mathrm{M}$ coronal sections into icecold $0.05 \mathrm{M}$ Tris buffered saline (TBS). Free-floating sections were processed in $13 \mathrm{ml}$ gooch crucibles used as baskets to transfer sections between solutions in order to keep tissue handling to a minimum. Sections were washed in $0.05 \mathrm{M}$ TBS, reacted with hydrogen peroxide $\left(\mathrm{H}_{2} \mathrm{O}_{2}\right)$ in $\mathrm{MeOH}$, preincubated in a blocking solution of normal goat serum (NGS), lysine, and Triton-X in TBS, and then incubated with the primary antiserum diluted in a similar solution (anti-GABA 1:5001:1000) for up to $14 \mathrm{~d}$ at $4^{\circ} \mathrm{C}$. Antiserum (kindly provided by Dr. R. Wenthold) was raised in rabbits against GABA conjugated to bovine serum and has previously been characterized (Wenthold et al., 1986). After labeling with the primary antibody, sections were incubated with goat anti-rabbit HRP (GAR-HRP) 1:100 in NGS and TBS. Reaction of the IgG-HRP with 3,3'-diaminobenzidine tetrahydrochloride in the presence of $\mathrm{H}_{2} \mathrm{O}_{2}$ forms a dark brown, amorphous precipitate which is insoluble in water and alcohols (Grzanna, 1982). Tissue from 3 pairs was also treated with cobalt chloride, which darkens the reaction product to a blue-black. Sections were then mounted on gelatin-subbed slides, dehydrated, and coverslipped.

A 50-mesh copper grid commonly used to support tissue for electron microscopy was carefully attached with cyanoacrylic to the area of each slide containing the IC sections in order to delineate a fixed area for quantitative analysis. Sections from the rat IC were compared to stereotaxic sections from a standard rat atlas (Paxinos and Watson, 1982) and matched descriptions by Rockel and Jones (1973) and Morest and Oliver, (1984). Only sections between bregma -8.8 and bregma -9.3 (Paxinos and Watson, 1982) were chosen. Preliminary studies suggested that the greatest loss of GABA-containing neurons is restricted to the ventrolateral aspects of the CIC. To ensure that similar areas were compared, this study focused on grid squares within the ventrolateral part of the CIC. Sections were examined in a blinded paradigm under a Wild compound microscope fitted with a Dage 65 MKII video camera and coupled to a high-resolution monochrome monitor at 2 magnifications (screen magnifications $=595 \times$ and $5700 \times$ ) with the latter allowing visualization of both nuclei and nucleoli. Immunoreactive profiles within predefined regions were identificd, mapped, counted, and stored for further analysis (Bioquant II, Digitizing Morphometry). The criteria for identifying immunostained neurons included the presence of a dark brown reaction product within cytoplasmic boundaries. Data were gathered from a minimum of 15 sections from each animal, and a distribution pattern similar to Roberts et al. (1985) was generated. Tissue from 5 pairs of animals was used at the higher magnification for cell area measurement. The tissue from 3 pairs which had been intensified with cobalt chloride was unsuitable, as the reaction product obscured the nucleolar profile.

Neurochemistry. For the second set of experiments, release of endogenous amino acids was measured using techniques described by Arneric et al. (1986). Release of ${ }^{3} \mathrm{H}-\mathrm{ACh}$ was analyzed using modifications of the radiochemical method developed by Hadhazy and Szerb (1977) and described by Arnerić and Reis (1986).

Briefly, 8 young adult (3- to 7-month-old) and 8 aged (20- to 26month-old) Fischer-344 rats were paired and killed by decapitation to process the animals concurrently. The brains were rapidly removed and placed in ice-cold modified Krebs bicarbonate buffer containing (mM) $\mathrm{NaCl}, 118 ; \mathrm{KCl}, 5 ; \mathrm{MgSO}_{4}, 1.2 ; \mathrm{NaHCO}_{3}, 25 ; \mathrm{D}$-glucose, $11 ; \mathrm{NaH}_{2} \mathrm{PO}_{4}$, $1.2 ; \mathrm{CaCl}_{2}, 1.2 ;$ physostigmine, 0.1 ; and choline chloride, 0.001 . Coronal sections $(0.5 \mathrm{~mm}$ thick) were prepared with a McIlwain tissue chopper and slices containing the IC were selected. Areas of the central nucleus were bilaterally dissected using the micropunch $(1.5 \mathrm{~mm}$, i.d. $)$ technique and incubated for $20 \mathrm{~min}$ at $37^{\circ} \mathrm{C}$ in Krebs bicarbonate buffer gassed with $95 \% \mathrm{O}_{2} / 5 \% \mathrm{CO}_{2}$, which also contained $100 \mu \mathrm{Ci} / \mathrm{ml}{ }^{3} \mathrm{H}$-methylcholine (Amersham, $80 \mathrm{Ci} / \mathrm{mmol}$ ). Micropunches of the CIC were transferred to superfusion vessels, which were constructed by joining 2 3-mm Acro LC3S disposablc $(0.45 \mu \mathrm{m})$ filter assemblies (Gelman) and maintained at $37^{\circ} \mathrm{C}$.

Micropunches of the IC were superfused at $5 \mathrm{~min}$ intervals (fractions) with $200 \mu$ l of fresh buffer contained within a $3 \mathrm{ml}$ syringe attached to the superfusion vessel by a luer lock mechanism. After a baseline collection period of 40-60 min, spontaneous release of neurotransmitters was assessed. Evoked release of neurotransmitters was measured after exposing the tissue to $35 \mathrm{mM} \mathrm{K} \mathrm{K}^{+}$. Increased $\mathrm{K}^{+}$concentrations were compensated by equiosmolar reductions in $\mathrm{Na}^{+}$concentrations. To determine the $\mathrm{Ca}^{2+}$ dependence of neurotransmitter release, 5 additional young (3- to 7-month-old) rats were used, and the Krebs bicarbonate solution was modified by replacing $\mathrm{Ca}^{2+}$ with $\mathrm{Mg}^{2+}(1.2 \mathrm{~mm})$. All fractions were collected into microcentrifuge tubes containing perchloric acid at a final concentration of $0.1 \mathrm{~N}$. Samples were stored at $-20^{\circ} \mathrm{C}$ for later analysis of ${ }^{3} \mathrm{H}-\mathrm{ACh}$ and amino acids.

Endogenous GABA, glutamate (Glu), aspartate (Asp), and tyrosine (Tyr) were measured by the HPLC technique described by Arneric et al. (1986), which is based on the method of Jones et al. (1981) using precolumn derivatization of amino acids with $o$-phthaldehyde. Briefly, superfusate samples were thawed, immediately neutralized using $0.5 \mathrm{M}$ sodium phosphate buffer (pH 10.5) and loaded into a Gilson model 231 automated sample injector. Samples $(20 \mu \mathrm{l})$ of derivatized amino acid components were separated on a reverse-phase, Altex Ultrasphere ODS column $(150 \times 4.6 \mathrm{~mm}$, i.d.; particle size, $5 \mu \mathrm{m})$. The elution of amino acid derivatives, including Asp, Glu, GABA, and Tyr was monitored using a Gilson (model 121) fluorescence spectrophotometer equipped with a $20 \mu \mathrm{l}$ flow-through cell. The excitation monochrometer was adjusted to $349 \mathrm{~nm}$ ( $20 \mathrm{~nm}$ slit), while emission was monitored at 446 $\mathrm{nm}(20 \mathrm{~nm}$ slit). Total analysis timc was $52 \mathrm{~min}$, and the limit of detection for this method was 100-200 fmol, although routine analysis required a detection range of $0.5-5.0$ pmol.

Radiolabeled ACh was routinely separated using the enzymatic liquid-cation exchange method described previously (Arneric and Reis, 1986). Briefly, superfusate $(100 \mu \mathrm{l})$ was incubated for $30 \mathrm{~min}$ at $37^{\circ} \mathrm{C}$ in a final volume of $200 \mu \mathrm{l}$ containing (in mM): $\mathrm{NaH}_{2} \mathrm{PO}_{4}, 100$ ( $\mathrm{pH} 8.5$ ); ATP, $0.36 ; \mathrm{MgCl}_{2}, 6.0$; and $50 \mu \mathrm{g} / \mathrm{ml}$, choline kinase. The reaction was stopped by placing the sample on ice, adding $0.5 \mathrm{ml}$ tetraphenylboron in 2-heptanone, and the microcentrifuge tube was shaken vigorously. The samples were centrifuged, the organic layer containing radioactive 
Table 1. Age-related loss of GABA immunostained CIC neurons

\begin{tabular}{ccccc} 
& \multicolumn{2}{l}{ GABA cell population densities } & & \multicolumn{2}{l}{ Mean area or GABA neurons } \\
\cline { 2 - 3 } & Cells $/ \mathrm{mm}^{2}$ & $\%$ Change & Area $\left(\mu \mathrm{m}^{2}\right)$ & \% Change \\
\hline Young adult & $145(n=8)$ & $36 \%$ decrease ${ }^{a}$ & $244(n=6)$ & $1 \%$ decrease $^{b}$ \\
vs aged & $93(n=8)$ & & $242(n=6)$ & \\
\hline
\end{tabular}

$a p<0.007$.

bS.

ACh was removed, and the extraction was repeated with another 0.5 $\mathrm{ml}$ tetraphenylboron in 2-heptanone. The radioactivity in the organic layer was determined by standard liquid scintillation counting methods (LS-5801, Beckman Instruments). Studies indicate that $98 \%$ of the radioactivity in the organic phase corresponds to authentic ACh as assessed by HPLC (Arnerić et al., 1988).

The tissue was homogenized by sonication in $250 \mu 1$ of $5 \mathrm{~mm} \mathrm{~K} \mathrm{~K}^{+}$ Kreb's bicarbonate buffer and stored in $0.1 \mathrm{~N}$ perchloric acid at $-20^{\circ} \mathrm{C}$ for future analysis. The samples were thawed on ice, centrifuged at $14,000 \times g$ for $2 \mathrm{~min}$, and $50 \mu \mathrm{l}$ of the sample was neutralized with an equal volume of $0.5 \mathrm{M}$ sodium phosphate buffer $\mathrm{pH} 10.5$ and loaded into a Gilson model 231 automated sample injector for IIPLC analysis as described above.

Statistics. The values obtained from each experimental group are means \pm SEM. Statistical analysis of immunocytochemical data was performed using independent-groups $t$-test, that of neurochemical data using 1-way analysis of variance (ANOVA). Duncan's new multiplerange test was employed to detect treatment differences. Although data are graphically represented as percentages of control, statistical analysis was performed only on absolute values from each experimental group. The criterion of statistical significance was $p<0.05$.

\section{Results}

GABA immunoreactivity

$\Lambda$ comparison of $\mathrm{G} \Lambda \mathrm{B} \Lambda$ immunoreactivity in selected sections from a young-adult and an aged Fischer-344 rat suggests an agerelated loss of labeled neurons or possibly loss of GABA staining from the ventrolateral region of the rat CIC (Fig. 1). A 36\% decrease $(p<0.007)$ in the number of GABA-positive neurons in the ventrolateral portion of the central nucleus of the IC for 8 aged rats was observed when compared with their paired young-adult cohorts. Pooled results presented in Table 1 are displayed graphically for each individual pair $(n=8)$ of youngadult/aged animals in Figure 2 (bar graph). These data indicate a reduction in the number of GABA-labeled neurons per square millimeter in the ventrolateral CIC for the aged animals.

In contrast to the reduction in cell number, when the 2-dimensional area of GABA-labeled IC neurons displaying nuclei and nucleoli was measured no significant age-related differences were observed (Table 1). The cross-sectional area of GABApositive cells was measured in 1 plane of focus. Immunoreactive profiles were seen to fall into 3 ranges, those cells of $<150 \mu \mathrm{m}^{2}$ (small), those of 150-350 $\mu \mathrm{m}^{2}$ (medium) and those of larger than $350 \mu \mathrm{m}^{2}$ (large) (Table 2). All 3 sizes can be seen in Figure 3. At the upper size range of GABA-positive neurons, some GABA-positive fusiform profiles were observed (Fig. 3). Immunoreactive puncta were observed both on neurons displaying GABA-like immunoreactivity and unstained neurons (Fig. 3). It was not possible to classify neuronal types accurately with the section thickness and counterstains used in this study. Sizes were comparable to those reported in the IC of the SpragueDawley rat described as 3 subpopulations of IC stellate (multipolar) cells ranging in size (diameter) between 10-30 $\mu \mathrm{m}$ (Moore and Moore, 1987) and in the gerbil IC (Roberts and Ribak,
1987) using glutamic acid decarboxylase (GAD)-like immunoreactivity to label GABA neurons. In Nissl-stained material, Faye-Lund and Osen (1985) described IC cells with diameters of $<10 \mu \mathrm{m}$ and those of 10-20 $\mu \mathrm{m}$ and larger.

\section{Neurotransmitter release}

The $\mathrm{K}^{+}$(35 mM)-evoked release of endogenous amino acids GABA, Glu, Asp, Tyr, and ${ }^{3} \mathrm{H}$-ACh from micropunches of the $\mathrm{CIC}$ in young (3- to 7-month-old) animals is illustrated in Figure 4. The ovcrflow of GABA, Glu, Asp, and ${ }^{3} \mathrm{H}-\mathrm{ACh}$ was significantly increased by $35 \mathrm{~mm} \mathrm{~K} \mathrm{~K}^{+}(220,215,163$, and $319 \%$ of basal efflux, respectively, $n=13, p<0.05$ ). In contrast, depolarization with $\mathrm{K}^{+}$failed to have a significant effect on the efflux of Tyr. The increased efflux of GABA, Glu, Asp, and ${ }^{3} \mathrm{H}-$ ACh evoked by $35 \mathrm{~mm} \mathrm{~K}^{+}$in the presence of $1.2 \mathrm{mM} \mathrm{Ca}^{2+}$ was virtually abolished in a $\mathrm{Ca}^{2+}$-free medium, not showing a significant difference from basal release in the presence of $\mathrm{Ca}^{2}$ । (Fig. 5). However, the release of Tyr was not sensitive to the exclusion of $\mathrm{Ca}^{2+}$ from the perfusing medium (data not shown). These findings support the hypothesis that GABA, Glu, Asp, and $\mathrm{ACh}$, but not Tyr, may have a role as chemical neurotransmitters in the CIC as previously proposed.

\section{Selective age-related impairment of $G A B A$ release}

With the exception of GABA, both the basal and evoked efflux of Glu, Asp, and ${ }^{3} \mathrm{H}-\mathrm{ACh}$ revealed a similar quantitative pattern in aged rats (Fig. 4). Release of GABA was substantially reduced in aged animals. When 8 matched pairs were compared, the basal and evoked release of GABA in aged animals was 65 and $58 \%$ of young controls, respectively $(p<0.05)$. However, the basal or evoked release of excitatory amino acids Glu and Asp or ${ }^{3} \mathrm{H}-\mathrm{ACh}$ did not reveal statistically significant age-related differences.

In order to establish whether the tissue content of GABA was reduced or if decreased availability of the major GABA precursor Glu may contribute to the loss of GABA with aging, the postrelease tissue levels of endogenous GABA, Glu, Asp, and Tyr in the CIC of young and aged rats were determined. The

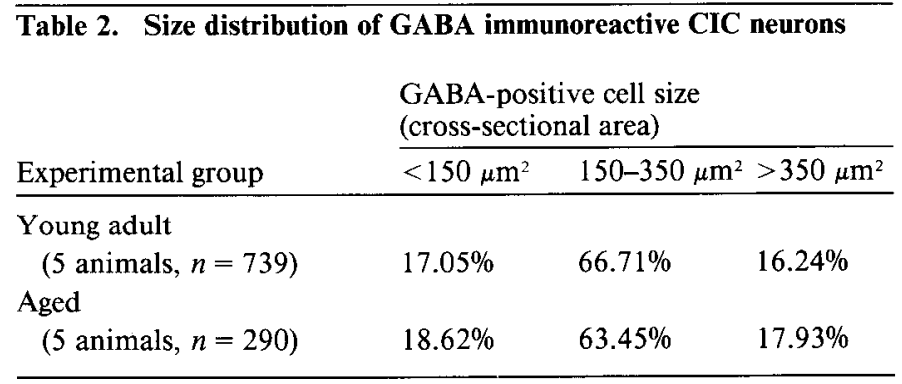



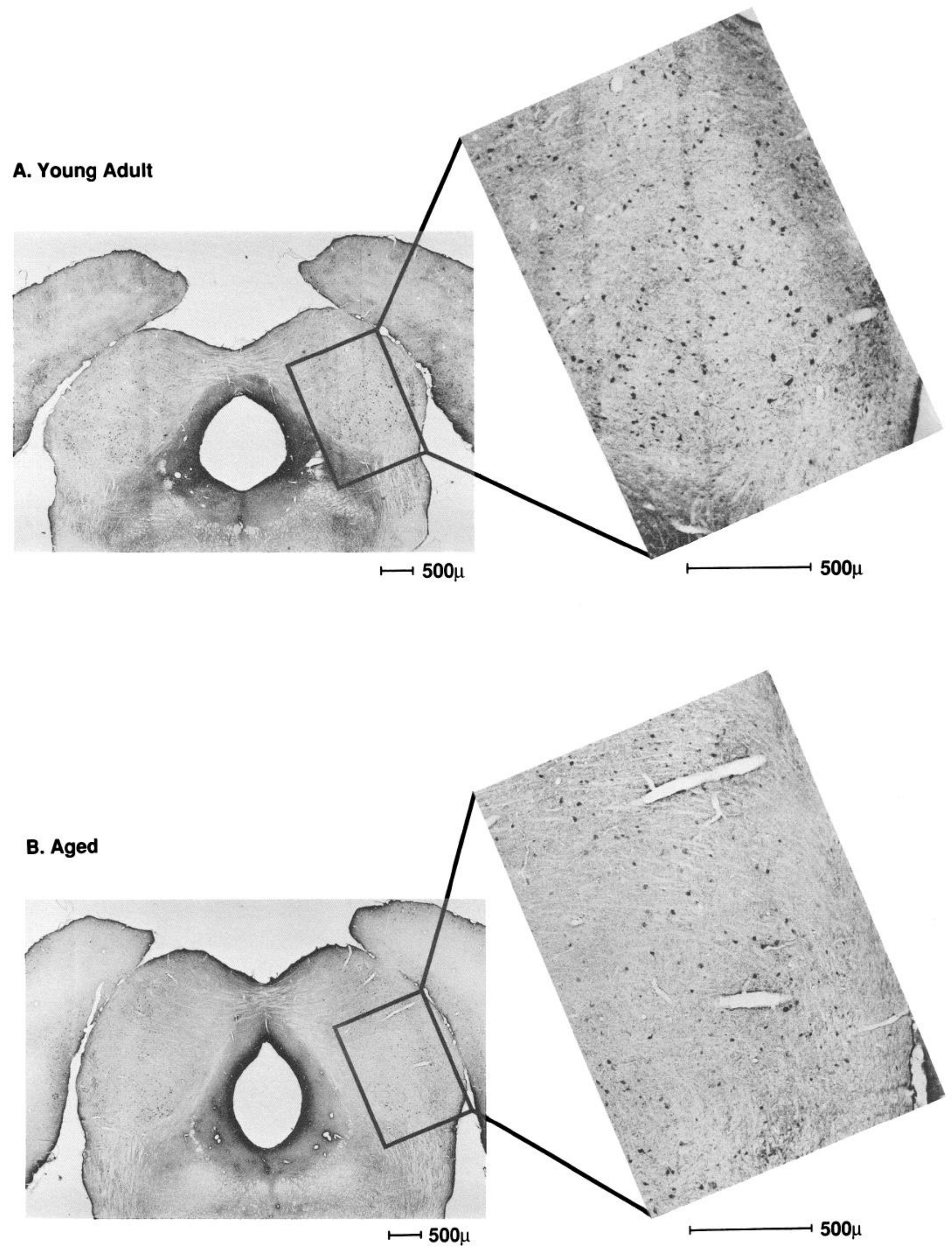

Figure 1. GABA-immunoreactive neurons are seen scattered throughout the IC in coronal sections of young adult ( 3 months) $(A)$ and aged $(28$ months) (B) Fischer-344 rats. Boxed area, GABA-immunoreactive neurons from the same sections at a higher magnification. 
Comparison of GABA - Positive Neurons in

Young Adult vs. Aged Rat I.C.

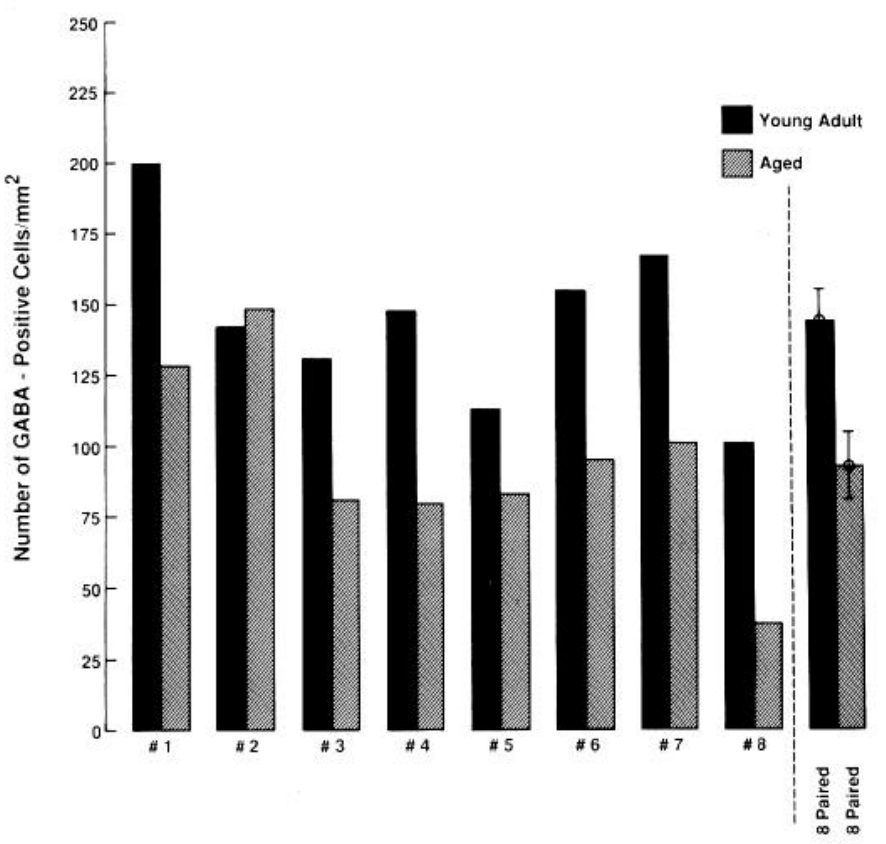

Figure 2. Bar graph showing the number of GABA-labeled neurons in the ventrolateral portion of the CIC for 8 young adult (2-3-month old) and 8 aged animals (18-29 months) processed as matched pairs. Pooled data for the 8 matched pairs are displayed at the right. Bars represent SEM.

content of free amino acids was measured in the micropunches at the end of the release experiments using HPLC (Table 3). Although these values are not truly reflective of in vivo steadystate amino acid levels, they do provide useful correlative information. A $30 \%$ decline in the tissue content of GABA was observed in aged rats compared to young animals $(p<0.05, n$ $=8$ ). However, the levels of Glu, Asp, and Tyr did not show a significant age-dependent difference. These findings complement the immunocytochemical and release data suggesting that the age-related reduction in tissue levels of GABA is the result of a loss of GABA-containing neurons and not of a decreased precursor availability or defective release.

To determine the regional specificity of GABAergic reduction, the release of endogenous GABA from the CIC was compared with 2 other important, nonauditory sensory areas, the rostral ventrolateral medulla (RVL) and the somatosensory cortex (SSCx). As with the IC, GABA has been proposed to be the major inhibitory neurotransmitter in the RVL and SSCx (Sun and Guyenet, 1986; Chagnac-Amitai and Conners, 1989). Micropunches from the 3 regions were obtained from the same rat to minimize the individual variation between animals. In contrast to the reductions in basal and evoked release of GABA in the CIC, no age-related effects were seen in the RVL or SSCx (Fig. 6). Release of Glu, Asp, ${ }^{3} \mathrm{H}-\mathrm{ACh}$, and Tyr also did not differ in RVL or SSCx of young and old rats (data not shown). Thus, the loss of GABA is regionally selective.

\section{Discussion}

This study provides immunocytochemical and neurochemical evidence that GABA is selectively reduced in the CIC of aged Fischer-344 rats. These findings, along with previously de- a

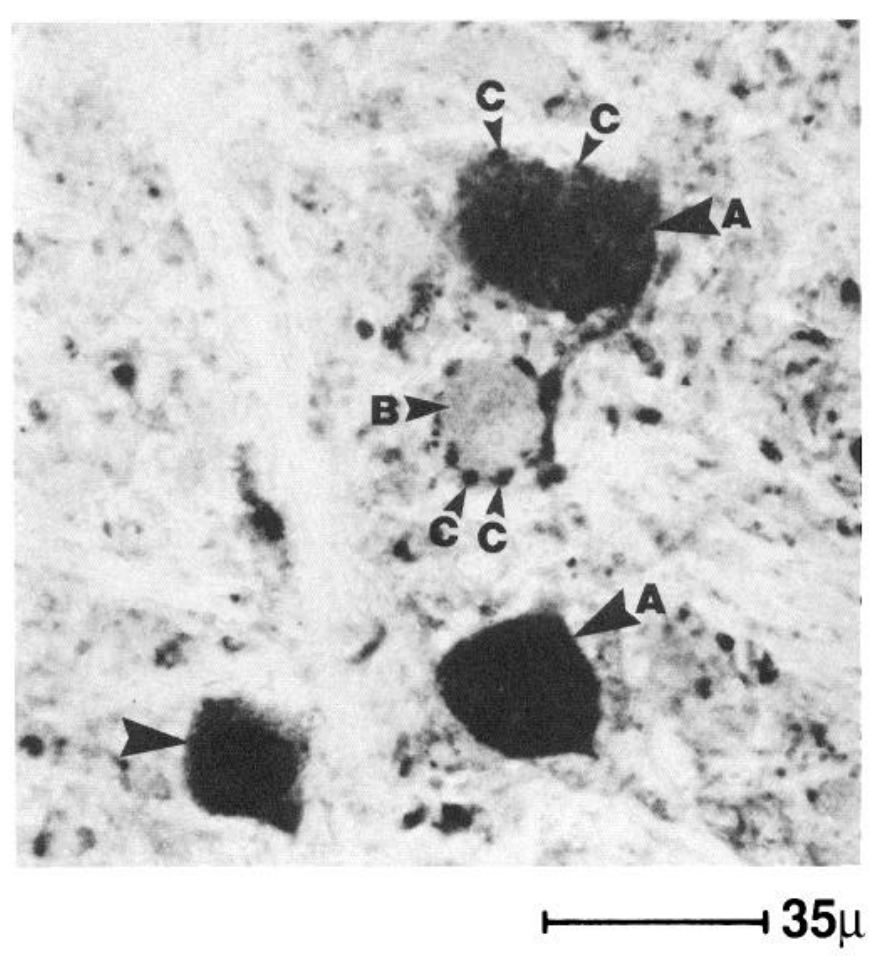

b

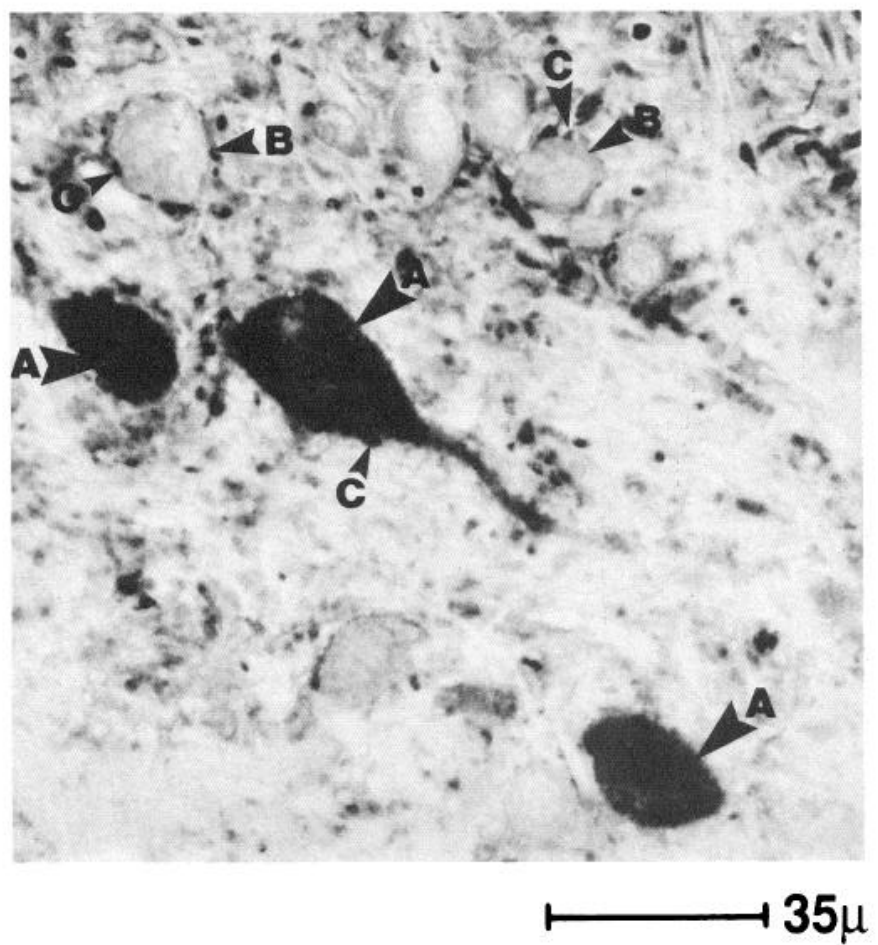

Figure 3. Examples of GABA-immunoreactive neurons (large arrows, A) of different sizes in the ventrolateral CIC of a mature Fischer-344 rat (see also Table 2). In $a$ there are medium/large immunoreactive profiles, while in $b$ there is a fusiform profile with an associated small cell. Somata showing no immunoreactivity are clearly visible (medium arrows, $B)$, while both immunoreactive and nonreactive neurons are seen to receive GABA-positive puncta (small arrows, $C$ ). 
Figure 4. Basal and $\mathrm{K}^{+}$-evoked release of endogenous GABA, Glu, Asp, and ${ }^{3} \mathrm{H}$-ACh from micropunches of the $\mathrm{CIC}$ in young (3- to 7 -month-old) and aged (20- to 26-month-old) Fischer-344 rats. Tissue was superfused with $5 \mathrm{~mm}$ (for basal efflux) and $35 \mathrm{~mm}$ (for evoked efflux) modified Krebs buffer containing $1.2 \mathrm{mM} \mathrm{Ca}^{2+}$. Fractions of $200 \mu \mathrm{l}$ were collected at the end of $5 \mathrm{~min}$ epochs. Basal and evoked release of ${ }^{3} \mathrm{H}-$ $\mathrm{ACh}$ and all amino acids consist of the mean of 3 values for each animal. Data represent means \pm SEM of values obtained from 8 pairs of young and aged animals. *Different at $p<0.05$ from basal release; $\dagger$ different at $p<0.05$ from young animals.

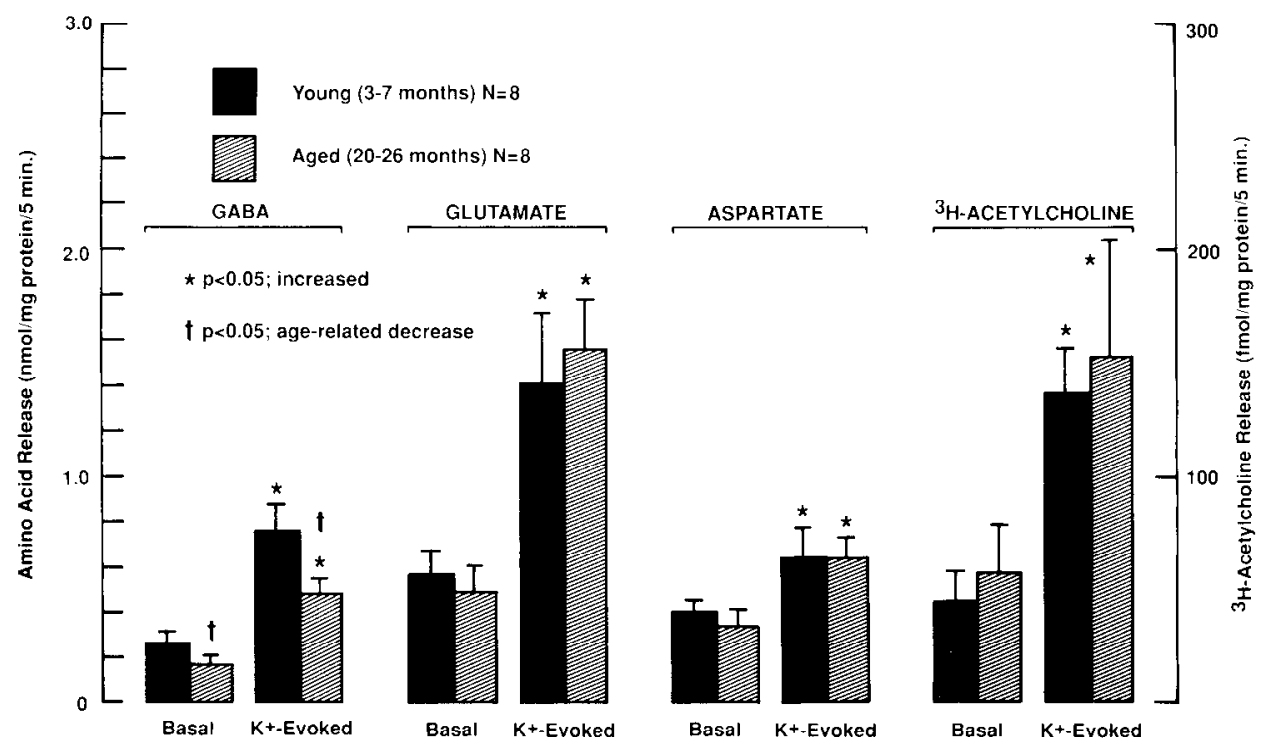

scribed impairments in acoustic processing and metabolic function in CIC, suggest that age-related loss of GABA in the CIC may affect audition. The precise role this deficit plays is not yet known, but this study clearly suggests GABA as a potential substrate of neural presbycusis that deserves further investigation.

Previous neurochemical and histochemical studies demonstrate high levels of GAD, GABA, and GABA-T in the CIC (Tachibana and Kuriyama, 1974; Fisher and Davies, 1976; Adams and Wenthold, 1979; Contreras and Bachelard, 1979; Ottersen and Storm-Mathisen, 1984; Nagai et al., 1985; Thompson et al., 1985; Moore and Moore, 1987), while neuropharmacological iontophoretic findings using GABA agonists and antagonists clearly implicate GABA to function as an inhibitory neurotransmitter in this structure (Faingold et al., 1989).

The major excitatory inputs to the CIC which may be subjected to local inhibition by GABA include: ascending inputs from the medial superior olive (MSO), lateral superior olive (LSO), and $\mathrm{CN}$ with extrinsic inhibitory inputs arising from the dorsal nucleus of the lateral lemniscus (DNLL) (Adams and Mugnaini, 1984; Oliver et al., 1987; Shneiderman and Oliver, 1987) and ventral nucleus of the lateral lemniscus (VNLL) (Adams and Wenthold, 1987), as well as from the low-frequency region of the LSO (Hutson and Glendenning, 1987; Saint Marie et al., 1989).

Neuronal degeneration in the central auditory neuraxis, including the $\mathrm{CIC}$, has been reported for human and primate brain (Kirikae et al., 1964; Hansen and Reske-Nielsen, 1965; Hoeffding and Feldman, 1989). However, the specific nature of the degenerating neurons in terms of their neurotransmitter status was not determined in these prior studies. A decreased number of GABA-positive neurons does not by itself imply degeneration. The loss of GABA immunostaining signifies undetectable levels of GABA which may also result from decreased synthetic enzyme activity in the absence of neuronal degeneration.

Studies of the auditory system in human and animal models indicate a number of changes occur with age. Cochlear loss of inner and outer hair cells has been reported, and age-related loss of eighth nerve fibers has been reported to be moderate in 22- to 23-month-old Sprague-Dawley rats and as high as 20\% in very old rats (Keithley and Feldman, 1979, 1982; Hoeffding and Feldman, 1987). Peripheral loss in Fischer-344 rats may be considerably less than that of Sprague-Dawley rats (E. M. Keithley, personal communication). However, as with all previous reports, this study does not distinguish whether the observed deficit in GABA neurons is secondary to loss of endorgan input resulting in transneuronal degeneration of GABA

Concurrent with a loss of these cells, others have demonstrated a significant age-related decrease in protein synthesis in both auditory and visual systems of the Sprague-Dawley rat (Ingvar et al., 1985). Studies in Fischer-344 as well as Sprague-Dawley rats have shown a $25 \%$ decrease in glucose utilization in the IC (London et al., 1981; Smith et al., 1986). Recent studies in the Fischer-344 rat using the 2-deoxyglucose method suggest that age-related changes occur in the IC in a regional and frequencydependent fashion (Clerici and Coleman, 1987).

ABR studies using click and tone pip stimuli exhibit changes in the aged Fischer-344 rat which include a prolonging of the predominant negative wave following wave IV $\left(\mathrm{N}_{\mathrm{o}}\right)$ and incrcases in interpcak latencies independent of the increase in wave I latency (Simpson et al., 1985; Cooper et al., 1986). These neurons or whether there is a primary concurrent dysfunction.

Table 3. Amino acid content of the inferior colliculus of young and aged Fischer-344 rats

\begin{tabular}{lllll} 
Experimental group & GABA & Glutamate & Aspartate & Tyrosine \\
\hline Young (3-7 months) & $65 \pm 9$ & $82 \pm 10$ & $116 \pm 15$ & $15 \pm 2$ \\
Aged (20-26 months) & $45 \pm 7^{a}$ & $81 \pm 11$ & $108 \pm 19$ & $12 \pm 2$
\end{tabular}

Values are means \pm SEM (nmol/mg protein); $n=8$.

${ }^{a}$ Value significantly decreased from the young animals, $p<0.05$. 


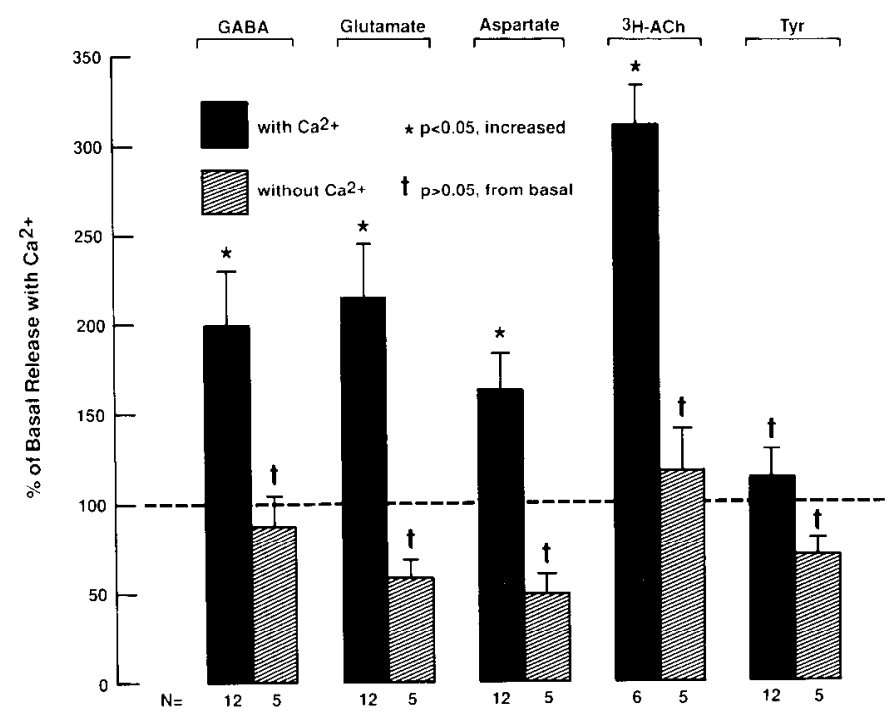

Figure 5. Effect of removing extracellular $\mathrm{Ca}^{2+}$ on the $\mathrm{K}^{+}$-evoked release of endogenous GABA, Glu, Asp, Tyr, and ${ }^{3} \mathrm{H}-\mathrm{ACh}$ from the micropunches of the $\mathrm{CIC}(0.5 \mathrm{~mm}$ thick, $1.5 \mathrm{~mm}$ diameter $)$ in young rats (3-7 months old). The micropunches were incubated with $\mathrm{Ca}^{2+}(1.2$ $\mathrm{mM}$ ) and $\mathrm{Ca}^{3+}$ frec modificd $\mathrm{Krcbs}$ buffer at $37^{\circ} \mathrm{C}$. Basal and evoked efflux were measured in response to buffers containing 5 and $35 \mathrm{~mm}$ $\mathrm{K}^{+}$, respectively ( $200 \mu \mathrm{l}$ aliquots over a 5 -min period). Data comprised values obtained in 10 independent experiments $(n=13)$ for $\mathrm{Ca}^{2+}$ dependent and 3 separate experiments $(n=5)$ for the $\mathrm{Ca}^{2+}$-independent release. Evoked release in both instances is computed as mean \pm SEM and expressed as percentage of basal release in the presence of $\mathrm{Ca}^{2+}$. *Different at $p<0.05$ from control; $\dagger$ not different at $p<0.05$ from the control group.

data suggest an age-related alteration of central transmission at the level of IC since wave IV and notch $\mathrm{N}_{\mathrm{o}}$ have been associated with IC function.

The IC plays a significant role in the localization of sound in space (Aitkin, 1986). IC neurons are sensitive to interaural time and intensity differences (Yin et al., 1986; Caird and Klinke, 1987). Most low-frequency CIC neurons are sensitive to interaural delays whereby the peak discharge rate is achieved in response to a critical time delay in the arrival of sound at the 2 ears (characteristic delay) irrespective of the spectral content of sound (Rose et al., 1966; Stillman, 1972; Yin and Kuwada, 1983). Ipsilateral sound stimulation suppresses the contralateral sound-evoked excitation of almost half of IC neurons, an effect which has been shown to be GABA-mediated (Rose et al., 1966; Faingold et al., 1989). Utilization of time and amplitude difference cues are not only critical for accurate localization of the direction of sound but also for enhancing speech intelligibility in a noisy environment (Herman et al., 1977). Elderly human subjects (60-72 years old) with normal hearing thresholds require twice the interaural time delay to attain the same level of performance as their younger counterparts (Herman et al., 1977). Similarly, aged Sprague-Dawley rats show significant impairments in accurate localization of the sound source as early as 18 months of age in the absence of peripheral hearing loss or deficits in motor and visual performance (Brown, 1984). These findings, which may in part reflect changes in the CIC, have important implications with regard to speech intelligibility in noisy auditory space, a characteristic finding in presbycusis (Jerger, 1973; Maurer and Rupp, 1979).

Electrophysiological correlates to the deficits in GABA neu-

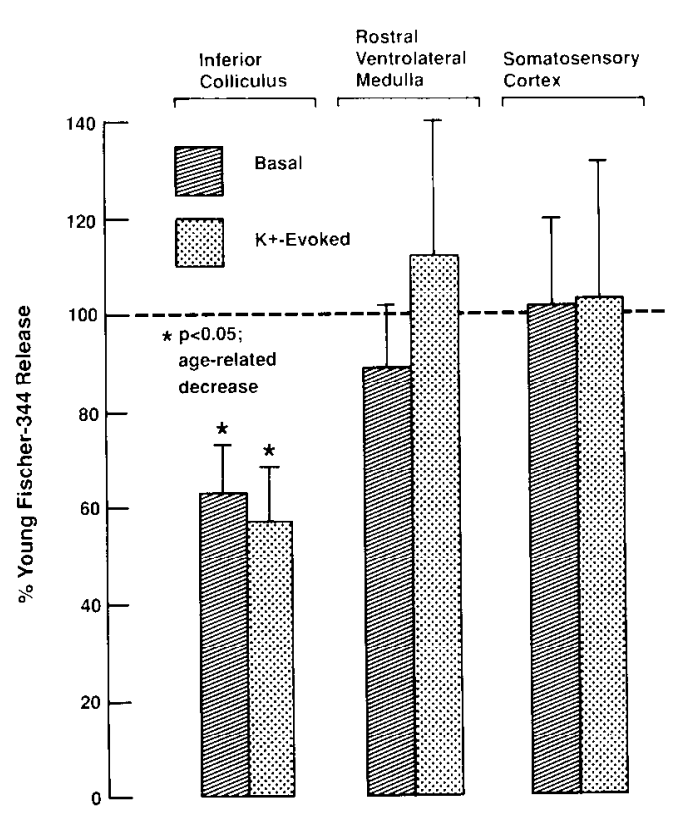

Figure 6. Basal and $\mathrm{K}^{+}(35 \mathrm{~mm})$-evoked release of endogenous GABA from the CIC, rostral ventrolateral medulla $(R V L)$ and somatosensory cortex $(S S C X)$ in aged (20- to 26-month-old) rats. Micropunches from each region were obtained from the same animals. Data represent means \pm SEM of values obtained from 8 pairs of young and aged animals for the CIC and 4 pairs of young and aged animals for RVL and SSCx. Final data are expressed as basal and evoked efflux of GABA in aged rats as percentages of the corresponding release in young controls. ${ }^{*}$ Different at $p<0.05$ from young animals.

rons reported here have been described in CBA $/ \mathrm{J}$ mouse (Willott et al., 1988a). Roughly $50 \%$ of neurons in the CIC display a nonmonotonic discharge pattern whereby the firing rate of units initially increases as a function of sound intensity to a certain level beyond which it decreases to levels sometimes approximating threshold (Rose et al., 1963; Semple and Kitzes, 1985). These nonmonotonic functions have been proposed to be the result of inhibitory circuits in the CIC (Aitkin, 1986). Exogenous application of the $\mathrm{GABA}_{\mathrm{A}}$ receptor antagonist bicuculline onto the CIC neurons converts the nonmonotonic response to a monotonic response, which suggests that the former may be GABA mediated (Faingold et al., 1989). Recently, Willot and coworkers (1988b) have shown that the percentage of neurons in the mouse CIC displaying nonmonotonic behavior declines from $48 \%$ in young animals to $19 \%$ in the senescent group $(60 \%$ reduction), which may lead to deficits in coding of acoustic information. It is conceivable that this age-related loss of nonmonotonicity in the CIC is due to GABAergic impairment. Moreover, increased spontaneous activity of collicular neurons which is most pronounced in the aging of the central nucleus has been reported (Willot et al., 1988a, b). The heightened spontaneous activity of CIC neurons may have implications pertaining to background neural noise and abnormal acoustic perception, e.g., tinnitus (Willot et al., 1988a, b).

Although the precise identification of the population of GABA neurons that mediates inhibition and the processing of acoustic information remains to bc detcrmined, this study provides evidence that age-related changes in release of GABA were from neuronal, and not glial, sources. The micropunch preparation employed for the release experiments consisted of spatially intact tissue with a heterogeneous cell population comprising 
both neuronal and glial constituents. Although glial cells contain significant amounts of GABA and other amino acids (Hertz, 1982; Reynolds and Herschkowitz, 1986), their contribution to depolarization induced release by $\mathrm{K}^{+}$is probably negligible from a functional point of view, and it shows a lesser degree of $\mathrm{Ca}^{2+}$ dependence compared to the release of neuronal origin (Hertz, 1979; Szerb, 1983). A number of studies in various preparations and brain regions indicate that $\mathrm{Ca}^{2+}$ dependency of $\mathrm{K}^{+}$-evoked release of GABA and possibly other proposed amino acid neurotransmitters is a reasonable criterion for establishing their neuronal origin (Walz, 1985). Therefore, it was important to delineate the relative contribution of each cell type to the observed release. Excluding $\mathrm{Ca}^{2+}$ from the perfusing medium virtually abolished the enhanced release of GABA, Glu, Asp, and ${ }^{3} \mathrm{H}$-ACh in response to $35 \mathrm{~mm} \mathrm{~K}{ }^{+}$, whereas it did not have a significant effect on the release of Tyr (Fig. 4). These data support the contention that the released amino acids and ${ }^{3} \mathrm{H}-\mathrm{ACh}$ are derived predominantly from a synaptic neuronal source.

The term "release" has been employed with the caveat that it signifies accumulation of substances in the superfusate during the 5 min epoch. Although the decrement in GABA release from the CIC of aged rats is approximately the same as the loss of GABA-positive neurons, several factors may influence the measured efflux either singly or in combination. These include (1) degeneration of GABAergic neurons and/or terminals; (2) decreased biological activity of the synthetic enzyme for GABA, GAD; (3) decreased availability of the major GABA precursor, Glu; (4) alterations in the uptake and/or degradative processes and changes in presynaptic $\mathrm{Ca}^{2+}$ influx; and (5) age-dependent alterations in the presynaptic receptor-mediated regulation of the release process. Most of these processes have been shown to undergo age-related changes in a number of brain regions, and it is possible that some of these alterations are operational in the aging CIC, thereby contributing to the GABAergic deficit.

The major pathway for GABA synthesis involves decarboxylation of Glu by GAD, and there is no evidence that significant amounts of GABA are formed through any other route. It is plausible, but unlikely, that decreased availability of Glu due to metabolic derangements with aging may lead to decreased GABA synthesis and thus contribute to the deficit. However, our data suggest that this is probably not the case for 2 reasons. First, we did not observe any difference in the basal or $\mathrm{K}^{+}$evoked release of Glu from the CIC between young and aged animals (Fig. 5). Second, the tissue content of Glu in both age groups was remarkably similar (Table 3 ). A recent report that surveyed tissue levels of amino acids throughout the brain found a similar significant age-related decline in IC tissue levels of GABA $(-22 \%)$ in Fischer-344 rats, with the loss of GABA most pronounced in the IC compared to other auditory nuclei (BanaySchwartz et al., 1989a, b). Levels of Glu and glutamine in IC did not show age-related differences (Banay-Schwartz et al., 1989a). Results in the present study are based on punches from the central nucleus of the IC, while the study cited included material taken from the entire IC, which could explain the more modest reductions reported by Banay-Schwartz and coworkers (1989a). Nevertheless, these data provide useful correlative evidence in support of our findings.

Age-related alterations in GABA uptake or degradation may affect the apparent release. While changes in GABA uptake or GABA-T activity in the CIC with aging have not been studied, evidence from the cerebral cortex and hypothalamus suggests that high-affinity GABA uptake is significantly decreased in aged rats (Wheeler, 1982, 1983). If a similar decrement in GABA uptake were presumed to exist in the CIC, one could speculate that the release data may in fact be an underestimation of the actual deficit in GABA as a function of age. Future experiments are in progress to clarify this issue.

It has also been hypothesized that a variety of age-related differences in cognitive function relate to signal-to-noise ratio within the CNS. This ratio is reduced with age (Crossman and Szafran, 1956; Cremer and Zeef, 1987). These authors suggest that signal strength could be degraded by diffuse neuronal loss or by a change in the level of inhibition and/or the noise level could be heightened by increased spontaneous activity. The aging CIC largely conforms to this theory. Diffuse neuronal loss (Kirikae et al., 1964; Hansen and Reske-Neilsen, 1965; Hoeffding and Feldman, 1989), loss of inhibition (Caspary and Lawhorn, 1987; Willott, 1988a, b), and increased spontaneous activity (Willott, 1988a, b) have all been reported for the CIC as a consequence of aging. The reduction in signal-to-noise ratio could have implications with reference to abnormal auditory perception and processing in advanced age.

The present study provides direct evidence for a major GABA deficit in the CIC as a function of aging. There is a body of evidence indicating that the CIC shows a variety of other alterations with aging. Some of these studies also suggest loss of inhibition as one of the possible changes. Considering the importancc of inhibitory functions in auditory processing, the selective loss of GABA in the $\mathrm{CIC}$ may have significant bearing on audition in the elderly. At the present time there is no known treatment for "neural" or "central" presbycusis. Future research aimed at identifying specific neurotransmitter changes in the central auditory system with aging and their functional consequences may provide information that targets possible development of pharmacotherapies for central presbycusis.

\section{References}

Adams JC, Mugnaini E (1984) Dorsal nucleus of the lateral lemniscus: a nucleus of GABAergic projection neurons. Brain Res Bull 13:585590.

Adams JC, Wenthold RJ (1979) Distribution of putative amino acid transmitters, choline acetyltransferase, and glutamate decarboxylase in the inferior colliculus. Neuroscience 4:1947-1951.

Adams JC, Wenthold RJ (1987) Immunostaining of ascending auditory pathways with glycine antiserum (abstr). Assoc Res Otolaryngol $10: 62$.

Aiktin L (1986) The cytoarchitecture of the mammalian auditory midbrain. In: The auditory midbrain: structure and function (Aitkin $\mathrm{L}$ ed), pp 31-46. Clifton, NJ: Humana.

Arnerić SP, Reis DJ (1986) Somatostatin and cholecystokinin octapeptide differentially modulate release of ${ }^{3} \mathrm{H}$-acetylcholine from caudate nucleus but not cerebral cortex: role of dopamine receptor activation. Brain Res 374:153-161.

Arnerić SP, Meeley MP, Reis DJ (1986) Somatostatin and CCK-8 modulate release of striatal amino acids: role of dopamine receptors. Peptides 7:97-103.

Arnerić SP, Honig MA, Milner TA, Greco S, Iadecola C, Reis DJ (1988) Neuronal and endothelial sites of acetylcholine synthesis and release associated with microvessels in rat cerebral cortex: ultrastructural and neurochemical studies. Brain Res 454:11-30.

Banay-Schwartz M, Lajtha A, Palkovits M (1989a) Changes with aging in the levels of amino acids in rat CNS structural elements I. Glutamate and related amino acids. Neurochem Res 14:555-562.

Banay-Schwartz M, Lajtha A, Palkovits M (1989b) Changes with aging in the levels of amino acids in rat CNS structural elements II. Taurine and small neutral amino acids. Neurochem Res 14:563-570.

Brown CH (1984) Directional hearing in aging rats. Exp Aging 10:3538. 
Caird D, Klinke R (1987) Processing of interaural time and intensity differences in the cat inferior colliculus. Exp Brain Res 68:379-392.

Carney LH, Yin TCT (1989) Responses of low-frequency cells in the inferior colliculus to interaural time differences of clicks: excitatory and inhibitory components. J Neurophysiol 62:144-159.

Caspary DM, Lawhorn BA (1987) Agc-rclatcd loss of GABA ncurons in the inferior colliculus. Soc Neurosci Abstr 13:545.

Chagnac-Amitai Y, Conners BW (1989) Horizontal spread of synchronized activity in neocortex and its control by GABA-mediated inhibition. J Neurophysiol 61:747-758.

Clerici WJ, Coleman JR (1987) Resting and pure tone evoked metabolic responses in the inferior colliculus of young adult and senescent rats. Neurobiol Aging 8:171-178.

Coleman JR, Clerici WJ (1987) Sources of projections to the subdivisions of the inferior colliculus in the rat. J Comp Neurol 262:215226.

Contreras NEIR, Bachelard HS (1979) Some neurochemical studies on auditory regions of mouse brain. Exp Brain Res 36:573-584.

Cooper WA, Coleman JR, Newton EH, Yoult AE (1986) ABR changes to tonal stimuli in the senescent Fischer-344 rat. Soc Neurosci Abstr $12: 1280$.

Cremer R, Zeef EJ (1987) What kind of noise increases with age? Gerontology 42:515-518.

Crossman ERFW, Szafran J (1956) Changes with age in the speed of information intake and discrimination. In: Experientia supplementum. IV. Symposium on experimental gerontology, pp 128-135. Basel: Birkhauser.

Faingold CL, Gehlbach G, Caspary DM (1986) Decreased effectiveness of GABA-mediated inhibition in the inferior colliculus of the genetically epilepsy-prone rat. Exp Neurobiol 93:145-159.

Faingold CL, Gehlbach G, Caspary DM (1989) On the role of GABA as an inhibitory neurotransmitter in inferior colliculus neurons: iontophoretic studies. Brain Res 500:302-312.

Fayc-Lund H, Osen KK (1985) Anatomy of the inferior colliculus in rat. Anat Embryol 171:1-20.

Fisher SK, Davies WE (1976) GABA and its related enzymes in the lower auditory system of the guinea pig. J Neurochem 27:1145-55.

Grzanna R (1982) Light microscopic immunocytochemistry with fixed unembedded tissues. In: Techniques in immunocytochemistry (Bullock GR, Petruzs P, eds), pp 183-204. New York: Academic.

Hadhazy P, Szerb JC (1977) The effect of cholinergic drugs on ${ }^{3} \mathrm{H}$ acetylcholine release from slices of rat hippocampus, striatum and cortex. Brain Res 123:311-322.

Hansen CC, Reske-Nielsen E (1965) Pathological studies in presbyacusis. Arch Otolaryngol 82:115-132.

Harrison JM (1981) Effects of age on acquisition and maintenance of a location discrimination in rats. Exp Aging Res 7:467-476.

Herman GE, Warren LR, Wagener JW (1977) Auditory lateralization: age differences in sensitivity to dichotic time and amplitude cues. $\mathbf{J}$ Gerontol 32:187-191.

Hertz L (1979) Functional interactions between neurons and astrocytes; turnover and metabolism of putative amino acid transmitters. Prog Neurobiol 13:277-323.

Hertz L (1982) Astrocytes. In: Handbook of neurochemistry (Lajtha A, ed), pp 326-332. New York: Plenum.

Hoeffding V, Feldman ML (1987) Changes with advanced age in the morphology of the rat auditory nerve. Soc Neurosci Abstr 13:1259.

Hoeffding V, Feldman ML (1989) The morphology of the inferior colliculus in young adult and aging macaques. Assoc Res Otolaryngol Abstr 105:93.

Hutson KA, Glendenning KK (1987) Biochemical basis for the acoustic chiasm? Soc Neurosci Abstr 13:548.

Ingvar MC, Maedar P, Sokoloff L, Smith CB (1985) Effects of ageing on local rates of cerebral protein synthesis in Sprague-Dawley rats. Brain 108:155-170.

Jerger J (1973) Audiological findings in aging. Adv Otorhinolaryngol 20:115-124.

Jones BN, Pajbo S, Stein S (1981) Amino acid analysis and enzymatic sequence determination of peptides by an improved $o$-pthaldehyde precolumn labeling procedure. J Liquid Chromatogr 4:565-586.

Keithley EM, Feldman ML (1979) Spiral ganglion cell counts in an age-graded series of rat cochleas. J Comp Neurol 188:429-442.

Keithley EM, Feldman ML (1982) Hair cell counts in an age-graded series of rat cochleas. Hear Res 8:249-262.

Kendall DA, Strong R, Enna SJ (1982) Modifications in rat brain
GABA receptor binding as a function of age. In: The aging brain: cellular and molecular mechanisms of aging in the nervous system (Giacobini E, Giacobini C, Filogamo G, Vernadakis A, eds), pp 211 221. New York: Raven.

Kirikae L, Sato T, Shitara T (1964) A study of hearing in advanced agc. Laryngcscope 74:205-220.

Kuwada S, Yin TCT, Haberly LB, Wickesberg RE (1980) Binaural interaction in the cat inferior colliculus; physiology and anatomy. In: Psychophysical, physiological, and behavioral studies in hearing. (van den Brink G, Bilsen FA, eds), pp 401-411. Delft: Delft U. P.

London ED, Nespor SM, Ohata M, Rapoport SI (1981) Local cerebral glucose utilization during development and aging of the Fischer-344 rat. J Neurochem 37:217-221

Maurer JF, Rupp RR (1979) The aging auditory process: presbycusis In: Hearing and aging, pp 33-63. New York, Grune \& Stratton.

Moiseff A (1985) Intracellular recordings from owl inferior colliculus. Soc Neurosci Abstr 1 1:735.

Moore JK, Moore RY (1987) Glutamic acid decarboxylase-like immunoreactivity in brainstem auditory nuclei of the rat. J Comp Neurol 260:157-174.

Morest DK, Oliver DL (1984) The neuronal architecture of the inferior colliculus in the cat: defining the functional anatomy of the auditory midbrain. J Comp Neurol 222:209-236.

Nagai T, Maeda T, Imai H, McGeer PL, McGeer EC (1985) Distribution of GABA-T-intensive neurons in the rat hindbrain. J Comp Neurol 231:260-269.

Oliver D, Shneiderman A, Henkel CK (1987) Morphological substrates for binaural interactions in the midbrain: afferents to the dorsal nucleus of the lateral lemniscus. Soc Neurosci Abstr 13:547.

Ottersen OP, Storm-Mathisen J (1984) Glutamate- and GABA-containing neurons in the mouse and rat brain, as demonstrated with a new immunocytochemical technique. J Comp Neurol 229:374-392.

Paxinos G, Watson C (1982) The rat brain in stereotaxic coordinates. Ncw York: Acadcmic

Reynolds R, Herschkowitz N (1986) Selective uptake of neuroactive amino acids by oligodendrocytes and astrocytes in primary dissociated culture; a possible role for oligodendrocytes in neurotransmitter metabolism. Brain Res 371:253-266.

Roberts RC, Ribak CE (1987) GABAergic neurons and axon terminals in the brainstem auditory nuclei of the gerbil. J Comp Neurol 258: 267-280.

Roberts RC, Ribak CE, Oertel WH (1985) Increased numbers of GABAergic neurons occur in the inferior colliculus of an audiogenic model of genetic epilepsy. Brain Res 361:324-338.

Rockel AJ, Jones EG (1973) The neuronal organization of the inferior colliculus of the adult cat. J Comp Neurol 147:11-60.

Rose JE, Greenwood DD, Goldberg JM, Hind JE (1963) Some discharge characteristics of single neurons in the inferior colliculus of the cat. I. Tonotopic organization, relation of spike-counts to tone intensity, and firing patterns of single elements. J Neurophysiol 26 : 294-320.

Rose JE, Gross NB, Geisler CD, Hind JE (1966) Some neural mechanisms in the inferior colliculus of the cat which may be relevant to the localization of a sound source. J Neurophysiol 29:288-314.

Saint Marie RL, Ostapoff EM, Morest DK, Wenthold RK (1989) A glycinc immunorcactive projection of the cat lateral superior olive: possible role in midbrain dominance. J Comp Neurol 279:382-396.

Semple MN, Kitzes LM (1985) Single unit responses in the inferior colliculus: different consequences of contralateral and ipsilateral stimulation. J Neurophysiol 53:1467-1482.

Shneiderman A, Oliver D (1987) Morphological evidence for inhibitory inputs to the inferior colliculus (IC) from the dorsal nucleus of the lateral lemniscus (DNLL). Soc Neurosci Abstr 13:1467.

Simpson GV, Knight RT, Brailowsky S, Prospcro-Garcia O, Scabini D (1985) Altered peripheral and brainstem auditory function in aged rats. Brain Res 348:28-35.

Smith CB, Goochee C, Rapoport SI, Sokoloff L (1986) Effects of ageing on local rates of cerebral glucose utilization in the rat. Brain 103:351365.

Smith PH (1986) Synaptic responses of neurons in brain slices of the guinea pig inferior colliculus. IUPS Satellite Symposium on Hearing, p 82.

Stillman RD (1972) Responses of high-frequency inferior colliculus neurons to interaural intensity differences. Exp Neurol 36:118-126. 
Sun M-K, Guyenet PG (1986) GABA-mediated baroreceptor inhibition of reticulospinal neurons. Am J Physiol 249:R672-R680.

Szerb JC (1983) Methods of GABA release. In: Glutamine, glutamate, and GABA in the central nervous system (Hertz L, Kvamme E, McGeer E, Schonsboe A, eds), pp 457-472. New York: Liss.

Tachibana M, Kuriyama K (1974) Gamma-aminobutyric acid in the lower auditory pathway of the guinea pig. Brain Res 69:370-374.

Thompson GC, Cortez AM, Lam DM-K (1985) Localization of GABA immunoreactivity in the auditory brainstem of guinea pigs. Brain Res 339:119-122.

Walz W (1985) Uptake and release of amino acid neurotransmitters. In: Neuromethods, Amino Acids (Boulton AA, Baker GB, Woods JD, eds), pp 239-272. Clifton, NJ: Humana.

Wenthold RJ, Zemple JM, Parakkal MH, Reeks KA, Altschuler RA (1986) Immunocytochemical localization of GABA in the cochlear nucleus of the guinea pig. Brain Res 380:7-18.

Wheeler DD (1982) Aging of membrane transport mechanisms in the central nervous system: GABA transport in rat cortical synaptosomes. Exp Gerontol 17:71-85.
Wheeler DD (1983) Aging of high affinity GABA transporter in synaptosomes from the hypothalamus of the rat. Exp Gerontol 18:125135 .

Willott JF, Parham K, Hunter KP (1988a) Response properties of inferior colliculus neurons in young and very old $\mathrm{CBA} / \mathrm{J}$ mice. Hear Res 37:1-14.

Willott JF, Parham K, Hunter KP (1988b) Response properties of inferior colliculus neurons in middle-aged $\mathrm{C} 57 \mathrm{BL} / 6 \mathrm{~J}$ mice with presbycusis. Hear Res 37:15-28.

Yin TCT, Kuwada S (1983) Binaural interaction in low frequency neurons in inferior colliculus of the cat. III. Effects of changing frequency. J Neurophysiol 50:1020-1042.

Yin TCT, Chan JCK, Irvine DRF (1986) Effects of interaural time delays of noise stimuli on low-frequency neurons in the cat's inferior colliculus. I. Responses to wideband noise. J Neurophysiol 55:280300 . 